\title{
A Family-The Tension and the Satisfaction
}

\section{Martin Vlček ${ }^{\mathrm{a}}$}

\begin{abstract}
Family members solve not only their interests, but make provision for interests of other members of the family, too. The space for the control at a higher level is thus formed. Without notifying, individual members in the process of provision making proceed depending on general rules of the organisation of elements into higher structures, as they exist in all stable objects. This provision making has different forms, starting with the love and ending with an assisted coexistence. The understanding of the role of individual controlling structures allows to improve the functioning of the family. Similarly, as a regular discussion of its functioning in the family and perhaps, their controlled casting by some of partners, too. The submitted work describes roles and the control in the elementary family—in the childless coexistence of partners.
\end{abstract}

\section{Keywords}

Family, tension, satisfaction, control, successfulness

Fundamental properties of every object are derived from the functioning of controlling structures. These structures function at different levels (Vlcek 2008; Vlcek 2010a; Vlcek 2015), with the same logic, despite of working with different elements. Goals and instruments are same.

The submitted work comes out from this philosophy. It uses findings from analogical systems and applies them in the family.

The identification of existing structures started through a long-term study at the macroeconomic level. With the help of a non-econometric model, the control structures of the economy and consequently of the whole society were discovered (Vlcek 2010b). Completion of this work was carried out using data from the New York Stock Exchange (Vlcek 2014).

\section{INITIAL NOTIONS}

Element of every system can be characterised by satisfaction and tension on its inputs, and by successfulness on its outputs.
The tension $\mathrm{PU}_{\mathrm{ab}}$ between entering interactions $\mathrm{a}$, $b$ is a function of a difference of their intensities, measured by their similarity. The satisfaction $\mathrm{S}$ is an average tension of all interactions entering into the element. The satisfaction with an input $S_{i}$ is a function proportional to the deviation of the intensity of the input from the average intensity of inputs. The successfulness $U$ is given as a summary intensity of outputting interactions from the element.

$\mathrm{PU}_{\mathrm{ab}}=\operatorname{div}\left(\left(\mathrm{abs}\left(\mathrm{h}_{\mathrm{ia}}-\mathrm{h}_{\mathrm{ib}}\right), \operatorname{dist}\left(\mathrm{p}_{\mathrm{a}}, \mathrm{p}_{\mathrm{b}}\right)\right) ; \mathrm{a}, \quad \mathrm{b} \in\right.$ Inputs),

div—a function correlating positively with intensities

$\mathrm{h}_{\mathrm{i}, \mathrm{b}}$ and negatively with distances, dist-distance of positions $\mathrm{p}_{\mathrm{a}}, \mathrm{p}_{\mathrm{b}}$.

aeFunctionality (Non-Profit Research Group), Prague, Czech Republic

\section{Correspondent Author:}

Martin Vlček, Na Plužině 356/16, 18200 Prague, Czech Republic

E-mail: martin.vlcek@efunctionality.eu 
$\mathrm{S}=\Phi\left(\mathrm{PU}_{\mathrm{ab}} ; \mathrm{a}, \mathrm{b} \in\right.$ Inputs $)$,

$\Phi$ - an average of all tensions.

$\mathbf{S}_{\mathrm{i}}=\mathrm{f}\left(\mathrm{h}_{\mathrm{i}}-\Phi\left(\mathrm{h}_{\mathrm{i}} ;\right.\right.$; $\in$ Inputs $)$,

f-function correlating positively with a deviation of intensity of the i-th input from the average of intensities

$\Phi$ of inputs into the element.

$\mathbf{U}=\Sigma\left(\mathrm{h}_{0} ;\right.$ o $\in$ Outputs $)$,

$\Sigma$-a sum of all intensities of outputs from the element.

\section{THE CONTROL OF A FAMILY}

\section{Elements}

The family as a system has a singularity. In contrast with other objects having a large number of elements, the discussed family has only two of them. But it has a large number of positions, and this is crucial for the functioning. Any member of the family-later on named as a partner - passes from one position to another depending on necessities of the system and thus it goes finally about a full-value system.

\section{The Central Axis-A Regeneration}

The regeneration of organisms of partners - materialistic and non-materialistic, too-is the fundamental function of the family, its central axis.

Two other structures of the control are around the central axis and its control there. They exist in all stabile objects in the nature (Vlcek 2008; Vlcek 2010a). The successfulness of individual partners in the process of regeneration is solved by the structure of control named EM0 - "empathy", the satisfaction of the whole family by the EM1 one.

These structures of the control are active at the moment when any partner evaluates his satisfaction and chooses his next procedure. At this same time, he makes to some extent provision for satisfaction of the other partner.

\section{The Control of the Axis-TOT}

There are different positions for the regeneration in the family. These positions are gradually occupied by partners and by their activities perform function, role of a position. Different home works, active repose, different supporting activities, etc., are concerned. These activities have to be to some extent coordinated, they have to concur and to have necessary suppositions formed. This is the space for a basic control structure, evolutionary the oldest one. Its speciality is in the fact to not to stem from a satisfaction of partners within their roles of controlled positions, but from their satisfaction within roles of consumers of regeneration. This control structure is later on named TOT_- "totalitarian".

The structure of TOT is in the family given by a certain "non-written" contract. At the process of the formation of a family, a distribution of positions into "male and female" happens. Thus it means that, e.g., the man is not controlled and advised at "male" positions and vice versa.

\section{EM0}

\section{The Satisfaction and the Successfulness}

The work of EM0, its control activity, stems from the satisfaction of partners in individual positions. The goal of this activity is to ensure the overall regeneration to be the maximally successful.

Every partner in every occupied position in the family-except positions of suppliers in EM1 (see) - is to some extent satisfied with inputs, received from other positions of the family. Mainly, these are positions of final consumers of the regeneration, which are feeling some satisfaction with its individual parts. It describes the extent of participation of any part on the overall regeneration and this satisfaction is possible to understand as a demand on it.

Further on, these are satisfactions of positions performing the regeneration. Their satisfaction 
concerns inputs, necessary in their activity. As, e.g., it is a cooperation of another position in the shopping of necessary materials or in the coordination of the activity—see work of TOT.

Thus every position in the family, except positions of users of the regeneration, will receive an amount of evaluations from corresponding positions. From this amount of evaluations, in EM0, the successfulness of individual positions, their usefulness throughout the regeneration in family is formed. And the successfulness is this value, upon what the control function of EM0 stands, and on what end is the successfulness of the overall regeneration.

It is interesting that the satisfaction of positions has two different sources. They stem from EM0 of individual partners at the position of users of regeneration, it means from a lower level, other positions from their EM1. Thus, here happens a connection of two different levels of the control: of the family and of a human.

\section{The Aggregation of the Successfulness}

EM0 aggregates successfulness into subsets $P$ in a manner how similar are activities worked by evaluated positions. The similarity is given by the proximity in the structure of the regeneration. These are subsets of materialistic and non-materialistic activities, in their frame, e.g., the control one. Every subset has its average successfulness and its deviation of successfulness.

$$
\begin{gathered}
\mathrm{P}=\left\{\mathrm{p}_{\mathrm{i}} ; \mathrm{i} \in \mathrm{I}, \max \left(\operatorname{dist}\left(\mathrm{p}_{\mathrm{a}}, \mathrm{p}_{\mathrm{b}}\right) ; \mathrm{a}, \mathrm{b} \in \mathrm{I}\right)<\right. \\
\max \left(\operatorname{dist}\left(\mathrm{p}_{\mathrm{c}}, \mathrm{p}_{\mathrm{d}}\right) ;\right.
\end{gathered}
$$

c $\in \mathrm{I}, \mathrm{d}$ non€ $\mathrm{I})\}, \mathrm{p}_{\mathrm{i}}$ - $\mathrm{i}$-th position in the subset $\mathrm{P}$, dist - similarity of positions, I-group of activities ( $\mathrm{P}$ is a subset of positions having among them a smaller distances than to any other out of the subset $\mathrm{P}$ ). These subsets, containing individual positions directly and later on named primary, aggregate by a similar key on, it means by the similarity of subsets into subsets of higher order. These have as element not positions but subsets represented by an average and deviation of their successfulness. And this process of aggregation continues up to the aggregation into one top subsets, characterizing the overall regeneration.

\section{Means and Goal}

At the work of EM0, there is one goal and two means. The goal is to augment the average successfulness of the overall regeneration and to diminish the deviation of successfulness of its components.

The first mean is the over-distribution of financial means, what family has to its disposal. The second one is the reconstruction of its structure of regeneration.

\section{Over-Distribution of the Fund}

The general strategy of over-distribution of financial means is the following of the successfulness. The more successful subset, at all levels, will receive more of means, than the lesser successful one. Because, from the economic point of view, the successfulness represents the demand for the concrete activity, this is the satiation of the demand.

\section{The Reconstruction of the Structure of Regeneration}

EM0 finds out primary subset with the biggest deviation and, at the same time, with the highest average successfulness. Then, the reconstruction consists in a reorganization of the structure in a manner to form a new position besides the most successful one with same relations and similar activity. And in the suppression or the total liquidation of the less successful position, by other words, the position being highly demanded is strengthened by a similar position and at the same time, the space for a next development is formed here, because it goes not about the quit same position.

EM0 can proceed also by forming only relations and not the whole positions. A new relation is formed from the most successful position of the subset and at the same time, EM0 liquidates relation from the less successful one. 


\section{EM1}

\section{The Border and the Tension}

Many goods and services enter into the family from its environment. Positions realizing these inputs are named later on as shoppers and they are also the place where the border, the interruption between inner and outer of family, passes. In the case of the family, this border is only functional, non-materialistic. It is controlled by a structure named EM1 and it is possible to observe the activity of this structure in properties and dynamics of the border.

The difference between similar inputs of shoppers and their non-similar successfulness, this is the tension on the border.

\section{The Tension and the Satisfaction}

EM1 similarly as EM0 forms subsets representing similar inputs with their successfulness. These can be similar social activities, similar materialistic inputs, etc.

Primary notions, as were introduced generally for an element, can be now transformed to the language of the family. $\mathrm{PU}_{\mathrm{ab}}$ is the tension between two shoppers. $\mathrm{PU}_{\mathrm{P}}$ is the tension of the subset $\mathrm{P}, \mathrm{PU}$ is the tension of the whole family. $S_{P}$ is the average successfulness of the subset $\mathrm{P}, \mathrm{S}$ is the summary successfulness - satisfaction of the family.

$\mathrm{PU}_{\mathrm{ab}}=\operatorname{div}\left(\left(\mathrm{abs}\left(\mathrm{U}_{\mathrm{a}}-\mathrm{U}_{\mathrm{b}}\right), \operatorname{dist}\left(\mathrm{p}_{\mathrm{a}}, \mathrm{p}_{\mathrm{b}}\right)\right) ; \mathrm{a}, \quad \mathrm{b} \in\right.$ Shoppers),

div-function positively correlating with successfulness $U_{a, b}$ and negatively with distances, dist—distance of positions $\mathrm{p}_{\mathrm{a}}, \mathrm{p}_{\mathrm{b}}$.

$$
\begin{aligned}
& \mathrm{PU}_{\mathrm{P}}=\max \left(\mathrm{PU}_{\mathrm{ab}} ; \mathrm{a}, \mathrm{b} \in \mathrm{P}\right) . \\
& \mathrm{PU}=\max \left(\mathrm{PU}_{\mathrm{P}} ; \mathrm{P} \in \text { subsets on the top level }\right) . \\
& \mathrm{S}_{\mathrm{P}}=\Phi\left(\mathrm{PU}_{\mathrm{ab}} ; \mathrm{a}, \mathrm{b} \in \mathrm{P}\right) \\
& \Phi-\text { average tension of the subset } \mathrm{P} . \\
& \mathrm{S}=\Phi\left(\mathrm{PU}_{\mathrm{P}} ; \mathrm{P} \in \text { subsets on the top level }\right) .
\end{aligned}
$$

Subsets are regrouped depending on their similarity until into a top level set. Its tension and satisfaction are at the same time tension and satisfaction of the whole family.

In its activity, EM1 uses two instruments, similarly as EM0. These are the redistribution of funds and the reconstruction of the border. The goal of EM1 is the growth of the satisfaction of the family and at the same time the decline of its tension.

\section{Funds}

The income of the family is redistributed similarly as in the case of EM0, but subsets are formed and redistributed not depending on the structure of regeneration, but depending on the similarity on the border. And similarly, the total income is redistributed depending on successfulness into individual lower subsets.

\section{The Reconstruction of the Border}

The reconstruction of the border has for its goal to remove important tension. This is a tension of a subset with a high average successfulness - importance.

The procedure of the solving is as follows. In a given subset, a new position is formed nearby the successful position of the solve tension, and the position with a low successfulness is cancelled. By other words, the reconstruction happens depending on well-tried positions. As result of this, not only the decrease of the tension and the growth of the successfulness of the subset happens, but of the family as whole.

\section{The Speech}

If the environment has to influence in the interest of the family, it means has to increase its satisfaction and to decrease its tension, it has to have the possibility of getting knowledge of them. The speech of the family as whole serves to this goal.

It seems that the principle is in the communication of the tension. Let our examined family, e.g., visits in its environment two other families. Let these two families can compare the frequency of these visits. If we suppose that visits are similar, the tension happens 
in the case when frequencies start to differ. By this tension, the family declare different satisfaction with similar inputs and this allows to families to react and to change these inputs.

Thanks to the activity of EM1 and due to the reconstruction of the border, the family searches out an environment, e.g., other families or social activities, where its satisfaction will growth.

\section{Localisation of EMO and EM1}

At every moment of evaluation of satisfaction and of the choice of the next proceeding at any position, a partner starts to fill the function of a position of EM0 or EM1, depending on circumstances. At every this decision, a partner realizes that she or he is a member of the family and that she or he has to make provision for interests of the second one. And just this provision making, this is a demonstration of the activity of the control structure.

Similar situation exists at the moment when some conflict happens, when conceptions of partners are different. Thus, a comparison of unequal conceptions and their modification comes on.

The activity of control structures leads in well functioning family to the fact, that the satisfaction of the family after apparition of short-lasting tensions starts every time for new growth.

\section{CONCLUSIONS}

What is the potential usage of the presented paper for the family itself? Apparently, it concerns structures EM0 and EM1, mainly. On them, the "aging" of family is the most striking, there the extinction of initial emissions happens. The manner of usage in both cases is analogical, triple. But in every case, the necessary condition is the interest of partners to maintain the family, eventually to improve it.

The first is the contribution of the understanding of the functioning of the control system itself. It means, of the completion of the spontaneous functioning by a more conscious approach.

The second, its role can play the "institutionalization", when regular "Friday Sessions" happen. Situations, normally solved spontaneously by structures, are analyzed there and solved "by hand". It is even possible to work with numeral evaluation of individual satisfactions and to follow their development.

The third and strong instrument represents the procedure, when partners do not rely on a subconscious, maybe assisted functioning, but one of partners takes over this control role, e.g., for a week. It means that the family is controlled normally, TOT is not changed, however, e.g., EM0 by one of partners enters into the play in every situation, when appropriate, e.g., when the satisfaction with the activity of TOT provokes some important tension.

\section{References}

Vlcek, M. 2008. "Functioning of the Object." Unpublished material.

_. 2010a. "Functioning of the Brain." ISB2010 Proceedings. Su Zhou, China.

- 2010b. "Movers of the Economy-Model of Interactions." Developments in Economic Theory and Policy Proceedings. Bilbao, Spain.

- 2014. "New Object Discovered Through the Stock Market." Presented at the International Conference on Economics and Finance Research Proceedings, Seoul, South Korea.

_. 2015. "Firm Without Subordinations." American Journal of Economics 5(3):333-336.

\section{Bio}

Martin Vlček, RNDr., ING., 15 years of macroeconomic forecasts in the Czech Ministry of Finances, eFunctionality (non-profit research group), Prague, Czech Republic; research field: cybernetics. 